\title{
New opportunities for the study of organic films applied on metals for corrosion protection by means of alternating current scanning electrochemical microscopy
}

\author{
Ricardo M. Souto ${ }^{1,2}$, Bárbara Socas ${ }^{1}$, Javier Izquierdo ${ }^{1}$, Juan J. Santana ${ }^{3}$ and Sergio \\ González ${ }^{1,2}$ \\ ${ }^{1}$ Department of Physical Chemistry, University of La Laguna, E-38200 La Laguna, Tenerife, Canary \\ Islands, Spain \\ 2 Instituto de Materiales y Nanotecnologías, University of La Laguna, E-38200 La Laguna, Tenerife, \\ Canary Islands, Spain \\ ${ }^{3}$ Department of Process Engineering, University of Las Palmas de Gran Canaria, Campus \\ Universitario de Tafira, E-35017 Las Palmas de Gran Canaria, Canary Islands, Spain.
}

\begin{abstract}
:
A new method for the investigation of the inhibition efficiency against corrosion by organic films adsorbed on metals based on the measurement of Z-approach curves by AC-SECM is proposed. Preliminary measurements conducted on four copper-inhibitor systems exposed to aqueous solutions support that a characteristic frequency can be defined, which corresponds to the frequency of the AC potential signal applied to the SECM tip for which a transition between negative- and positive-feedback behaviours is observed in the approach curves. From the shift of this characteristic frequency towards higher values, the enhancement of the corrosion protection efficiency of the inhibitor system can be established. Furthermore, the effects of inhibitor nature, concentration, and pre-treatment duration for the formation of the surface films, can be readily investigated.
\end{abstract}

\section{Keywords:}

Corrosion inhibition; alternating current scanning electrochemical microscopy; copper; benzotriazole; mercaptobenzimidazole; ethyl xanthate. 


\section{Introduction}

The alternating current mode of AC-SECM was first employed to achieve a more sensitive determination of the tip-substrate distance in SECM aiming measurements to have greater resolution especially in the case of potentiometric operation $[1,2]$. In this way, application of a high frequency $A C$ voltage signal to the tip, would facilitate more precise positioning since the resulting current signal flowing through the microelectrochemical cell greatly depends on the height of the electrolyte volume comprised between the tip and the substrate in electrolytes of sufficiently low conductivity $[1,3]$. Later studies demonstrated that the current response of the system is also affected by the conductive/insulating nature of the substrate, thus opening a wide range of applications for surface activity screening using more extended frequency ranges for the potential perturbation [4-6]. Applications of this technique to the study of corrosion processes have been demonstrated subsequently, namely for the detection of pinholes in coated metals [7], the monitoring of corrosion pits in otherwise passive metals [8], the visualization of selective dissolution reactions of alloys [9], and the characterization of thin inhibitor films on metals $[10,11]$. In the later case, this technique has been successfully employed to follow the kinetics of film formation [10], to characterize the corrosion resistance of the resulting metal-inhibitor films [11], and to visualize the degradation of these films under the corrosive attack of the environment [11].

Because the effectiveness of organic inhibitors is related to the extent to which they adsorb and cover the metal oxide surface, and AC-SECM is highly sensitive to the conductive/insulating characteristics of the resulting inhibitor films formed on the metals, it has been considered that the following step of this kind of studies would be the establishment of a platform for inhibitor screening using this technique based on determinations of inhibitor efficiencies for different inhibitor-metal systems. Usually, the efficiency of inhibitor systems is determined from gravimetric and electrochemical methods, with the highest resolution being provided by electrochemical impedance spectroscopy (EIS) [12-18], and the electrochemical quartz crystal microbalance (EQMB) [19-24]. Nevertheless, these techniques average the behaviour of all the surface exposed to the environment and do not provide direct information on the structure and composition of the surface films. This is the rationale for the use of ex situ surface analytical techniques in these investigations too, namely X-ray photoelectron spectroscopy (XPS), Auger electron spectroscopy (AES), secondary ion mass spectrometry (SIMS), and laser micro mass analysis (LAMMA) [25-30]. Again these techniques exclusively provide global information as they lack enough spatial resolution, which is demanded to better understand the nature of the interactions and processes responsible for the inhibiting effect. Such knowledge is highly needed to elucidate the mechanisms involved, and it would facilitate inhibition to be optimized. This is the justification for the application of scanning probe microscopies (SPM) in this research area. Yet, their application has been exclusively directed to monitor how metal dissolution in acids is affected by the presence of inhibitor films previously formed on the metal samples. Such effect is then evaluated by imaging the surface 
morphological changes occurring in micrometer and nanometer scales after various degrees of corrosive attack [31-35].

In this work, we have considered four well-known corrosion inhibitor molecules against copper corrosion as model systems for the investigation. The organic molecules are benzotriazole (BTAH), 5-methyl-benzotriazole (MBTAH), 2-mercaptobenzimidazole (MBI), and ethyl xanthate (EX). This choice of inhibitors allows us to take advantage of the well established relative inhibition efficiencies of these compounds, as to check information rendered by the new methodology based in the use of AC-SECM.

\section{Experimental}

\subsection{Materials}

The metallic substrates were $99.99 \%$ purity copper plates, supplied by Goodfellow (Cambridge, United Kingdom), which were cut to $2.4 \mathrm{~cm} \times 2.4 \mathrm{~cm}$ and $1 \mathrm{~mm}$ thickness. The surface of the samples was ground mechanically using metallographic emery paper to a 1500 grit finish, degreased with acetone, rinsed with MilliQ grade water and dried to air. For the preparation of the inhibitive films on the copper samples, the metal plates were immersed in $0.1 \mathrm{M} \mathrm{KCl}$ solutions containing $0.1 \mathrm{mM}$ concentration of the chosen inhibitor for different immersion times. Benzotriazole (Avocado Research Chemicals Ltd., UK), 5-methyl-1H-benzotriazole (Aldrich, USA), 2mercaptobenzimidazole (Aldrich, UK), and potassium ethyl xanthate (Fluka Chemica, Switzerland) were used as received. All aqueous solutions were prepared using ultra-pure water purified with a Milli-Q system from Millipore.

\subsection{Experimental procedure}

The SECM experiments were carried out using an AC-SECM built by Sensolitycs (Bochum, Germany), controlled with a personal computer. The electrochemical interface was an Autolab (Ecochemie, Utrecht, The Netherlands) electrochemical interface consisting of a bipotentiostat and a frequency response analyzer, though the system was operated in a three-electrode configuration since the coated sample was left unbiased for the duration of the experiments. Platinum microelectrodes (dia. 25 $\mu \mathrm{m}$ ) were employed as AC-SECM tips. An Ag/AgCl/saturated $\mathrm{KCl}$ reference electrode and a platinum wire used as counter electrode were also introduced in the small electrochemical cell, which was placed inside a Faraday cage. AC voltage signals of $100 \mathrm{mV}_{\mathrm{pp}}$ amplitude were applied in the 351 to $55493 \mathrm{~Hz}$ frequency range. A total of 26 frequency values were used, and the values spaced logarithmically. Testing was performed in naturally aerated $1 \mathrm{mM}$ $\mathrm{Na}_{2} \mathrm{SO}_{4}$ aqueous solution at ambient temperature.

\section{Results and discussion}


AC-SECM probes surface reactivity by recording $Z$-approach curves as the ultramicroelectrode approaches the sample. They are plotted as the magnitude of the dimensionless tip current (i.e. the ratio between the current value at each location to the stationary value measured in the bulk of the electrolyte), and $z / r$ is the dimensionless distance between the sample and the tip. The samples were left at their spontaneous open circuit potentials in the test electrolyte.

In the case of an insulating surface such as that of glass at the bottom of the electrochemical cell exposed to $1 \mathrm{mM} \mathrm{KCl}$, the approach curves show smaller currents than in the bulk of the electrolyte when the microelectrode moves closer to the glass surface (see Figure 1). Though the extent of such decrease varies with the applied AC frequency for a given tip-substrate distance, such a "negative feedback" behaviour occurs at all frequencies. The term "negative feedback" has been taken from the conventional amperometric SECM operation that uses a reversible diffusing redox mediator [36] for imaging. In that situation, an insulating substrate hinders diffusion of this species to the reactive surface of the tip thus leading to the measurement of smaller faradaic currents.

In the case of untreated copper, which is a conductive substrate, when it is immersed in 1 $\mathrm{mM} \mathrm{Na}_{2} \mathrm{SO}_{4}$, two trends are observed for the variation of the current magnitude with the tipsubstrate distance within the frequency range as shown in Figure 2. First, negative-feedback type Zapproach curves are measured in the low AC frequency range applied, whereas the opposite occurs at higher frequencies. In the later, the current magnitude progressively increases from its value in the bulk electrolyte as the tip moves towards the sample, and thus it exhibits "positivefeedback" behaviour. The magnitude of this positive feedback type effect is observed to be dependent on the frequency of the AC signal, and it is highest at the high frequency limit. The $Z$ approach curve determined at the frequency of $8966 \mathrm{~Hz}$ only exhibits a weak positive feedback effect. Obviously, this frequency value is only slightly higher than the frequency at which the transition from negative to positive feedback type behaviour occurs.

The protection characteristics conferred to copper surfaces by the organic molecules should result in a modification of the conductive properties of the surface, progressively adopting a more insulating behaviour as the adsorbed film becomes an effective barrier to electron transfer $[37,38]$, was investigated by recording Z-approach curves as the ultramicroelectrode approaches the sample. The inhibitor molecules considered in this work were benzotriazole (BTAH), 5-methyl-1Hbenzotriazole (MBTAH), 2-mercaptobenzimidazole (MBI), and potassium ethyl xanthate (EX). Inhibitor films were produced on the copper electrode ex-situ by dipping the freshly polished metal samples in a $100 \mathrm{mM} \mathrm{KCl}+0.1 \mathrm{mM}$ inhibitor solution for controlled immersion times. Figure 3 shows some Z-approach curves measured for inhibitor-treated copper samples during immersion in $1 \mathrm{mM} \mathrm{Na}_{2} \mathrm{SO}_{4}$. They correspond to the four inhibitor molecules after two different pre-treatment durations (namely 5 and $45 \mathrm{~min}$, respectively). 
Both positive- and negative-feedback trends are observed in all the cases, though the frequency range for either behaviour is observed to vary with both the nature of the inhibitor and the duration of the pre-treatment. In general, longer treatments lead to a narrower frequency range in which the positive-feedback is observed, a feature that is more pronounced in the case of the samples treated with EX, and the smallest changes are presented by MBI and MBTAH. This observation indicates that the blocking characteristics towards electron transfer can be followed from the shift of the frequency ranges for positive- and negative-feedback behaviours as determined from AC-SECM approach curves. Therefore, the frequency distribution of the normalized current values at the distance of closest approach can be used to follow the formation of insulating films of inhibitors on active metals, and to characterize the inhibiting frequency of metal-inhibitor systems. Figure 4 shows the resulting magnitude-frequency plots for the four model inhibitor systems, in which the behaviour for untreated copper has also been included. It can be readily observed that there is a shift in the characteristic frequency for the transition between negative- and positivefeedback behaviours to higher values with thicker inhibitor films. These graphs also allow to observe that the inhibitor films formed with $\mathrm{BTAH}$ and $\mathrm{MBTAH}$ after 5 minutes immersion exhibit similar characteristics to those obtained at longer exposures, whereas longer exposures are necessary to form the thicker films with EX. Additionally, aging of inhibitor films leading to a more compact layer is suggested to be responsible for the shift of the current magnitude values measured at the lowest $\mathrm{AC}$ frequencies with the elapse of time for the Cu-BTAH system, though this explanation is only temptative at this stage and requires further investigation.

\section{Conclusions}

Though the work is still in a rather preliminary stage, we think a novel experimental methodology to investigate the protection skills and the kinetics of film formation for metal-inhibitor systems by AC-SECM has been developed. The inhibitor films can be described on the basis of the transition frequency values between negative- and positive-feedback behaviours determined from $Z$-approach curves. This method is highly sensitive, and may offer new insights in the study of corrosion inhibition by organic films applied on metals.

\section{Acknowledgements:}

The authors are grateful to the Ministerio de Ciencia e Innovación (Madrid, Spain) and the European Regional Development Fund (Brussels, Belgium), within the framework of Project CTQ2009-12459, under which the present work was carried out. A Research Training Grant awarded to $\mathrm{JI}$ by the MICINN (Programa de Formación de Personal Investigador) is gratefully acknowledged. 


\section{References:}

1. B.R. Horrocks, D. Schmidtke, A. Heller, A.J. Bard, Anal. Chem. 65 (1993) 3605-3614.

2. M.A. Alpuche-Aviles, D.O. Wipf, Anal. Chem. 73 (2001) 4873-4881.

3. R.T. Kurulugama, D.O. Wipf, S.A. Takacs, S. Pongmayteegul, P.A. Garris, J.E. Baur, Anal Chem. 77 (2005) 1111-1117.

4. A.S. Baranski, P.M. Diakowski, J. Solid State Electrochem. 8 (2004) 683-692.

5. M. Etienne, A. Schulte, W. Schuhmann, Electrochem. Commun. 6 (2004) 288-293.

6. P.M. Diakowski, A.S. Baranski, Electrochim. Acta 52 (2006) 854-862.

7. B.B. Katemann, C.G. Inchauspe, P.A. Castro, A. Schulte, E.J. Calvo, W. Schuhmann, Electrochim. Acta 48 (2003) 1115-1121.

8. K. Eckhard, T. Erichsen, M. Stratmann, W. Schuhman, Chem. Eur. J. 14 (2008) 3968-3976.

9. D. Ruhlig, H. Gugel, A. Schulte, W. Theisen, W. Schuhmann, Analyst 133 (2008) 1700-1706.

10. M. Pähler, J.J. Santana, W. Schuhmann, R.M. Souto, Chem. Eur. J. 17 (2011) 905-911.

11. J.J. Santana, M. Pähler, W. Schuhmann, R.M. Souto, submitted (2011).

12. J.B. Cotton, I.R. Scholes, Brit. Corros. J. 2 (1967) 1-5.

13. G.W. Poling, Corros. Sci. 10 (1970) 359-370.

14. M.M. Laz, R.M. Souto, S. González, R.C. Salvarezza, A.J. Arvia, J. Appl. Electrochem. 22 (1992) 1129-1134.

15. S. González, M.M. Laz, R.M. Souto, R.C. Salvarezza, A.J. Arvia, Corrosion 49 (1993) 450-456.

16. K. Rahmouni, N. Hajjaji, M. Keddam, A. Shriri, H. Takenouti, Electrochim. Acta 52 (2007) 75197528.

17. M.M. Antonijević, S. Milić, M.B. Petrović, Corros. Sci. 51 (2009) 1228-1237.

18. J. Aljourani, K. Raeissi, M.A. Golozar, Corros. Sci. 51 (2009) 1836-1843.

19. Y. Yamamoto, H. Nishihara, K. Aramaki, J. Electrochem. Soc. 140 (1993) 436-443.

20. N. Ohno, J. Uehara, K. Aramaki, J. Electrochem. Soc. 140 (1993) 2512-2519.

21. D. Jope, J. Sell, H.W. Pickering, K.G. Weil, J. Electrochem. Soc. 142 (1995) 2170-2173.

22. A. Shaban, E. Kálmán, J. Telegdi, Gy. Dóra, J. Appl. Phys. A 66 (1998) 545-549.

23. E. Szöcs, Gy. Vastag, A. Shaban, G. Konczos, E. Kálmán, J. Appl. Electrochem. 29 (1999) 1339-1345.

24. Gy. Vastag, E. Szöcs, A. Shaban, I. Bertóti, K. Popov-Pergal, E. Kálmán, Solid State Ionics 141-142 (2001) 87-91.

25. R. Holm, D. Holtkamp, R. Kleinstück, H.-J. Rother, S. Storp, Fresenius Z. Anal. Chem. 333 (1989) 546-554.

26. D.M. Briggs, M.P. Seah (Eds.): Practical Surface Analysis. Vol. 1: AES and XPS. Wiley, New York, 1990. 
27. R.V. Varma, J.R. Selman (Eds.): Techniques for Characterization of Electrodes and Electrochemical Processes. Wiley, New York, 1991.

28. R.M. Souto, V. Fox, M. Pérez, M.M. Laz, S. González, Mater. Sci. Forum 192-194 (1995) 385394.

29. R.M. Souto, V. Fox, M.M. Laz, M. Pérez, S. González, J. Electroanal. Chem. 411 (1996) 161165.

30. T. Kosec, D.K. Merl, I. Milošev, Corros. Sci. 50 (2008) 1987-1997.

31. B.J. Cruickshank, A.A. Gewirth, R.M. Rynders, R. Alkire, J. Electrochem. Soc. 139 (1992) 28292832.

32. M.R. Vogt, A. Lachenwitzer, O.M. Magnussen, R.J. Behm, Surf. Sci. 399 (1998) 49-69.

33. W. Polewska, M.R. Vogt, O.M. Magnussen, R.J. Behm, J. Phys. Chem. B 103 (1999) 1044010451.

34. E. Szöcs, I. Bakó, T. Kosztolányi, I. Bertóti, E. Kálmán. Electrochim. Acta 49 (2004) 1371-1378.

35. A. Paszternák, S. Stichleutner, I. Felhösi, Z. Keresztes, F. Nagy, E. Kuzmann, A. Vértes, Z. Homonnay, G. Petö, E. Kálmán, Electrochim. Acta 53 (2007) 337-345.

36. A.J. Bard, F.-R.F. Fan, M. Mirkin, in Electroanalytical Chemistry, Vol. 18, A.J. Bard (Ed.). Marcel Dekker, New York, 1994, p. 243.

37. J. Izquierdo, J.J. Santana, S. González, R.M. Souto, Electrochim. Acta 55 (2010) 8791-8800.

38. J. Izquierdo, J.J. Santana, S. González, R.M. Souto, Mater. Chem. Phys. submitted (2010).

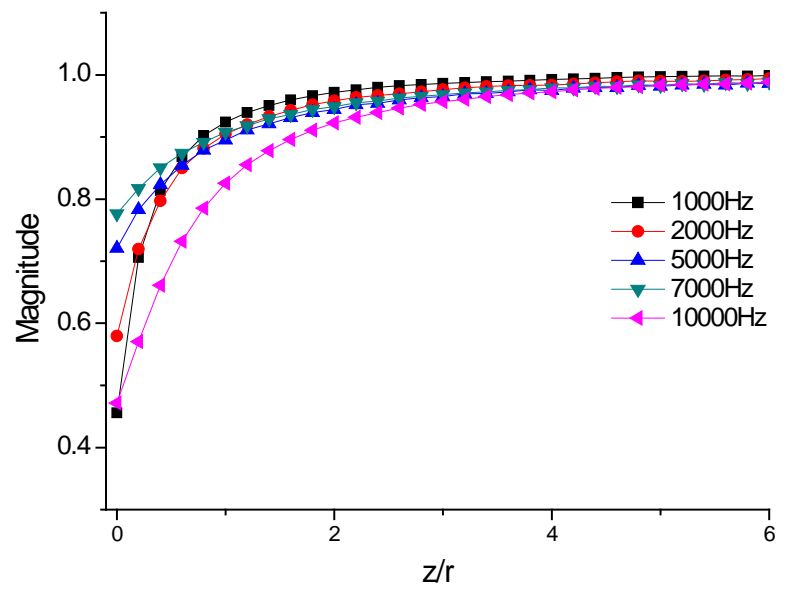

Figure 1: AC-SECM normalized Z-approach curves towards the glass bottom of the cell immersed in a $1 \mathrm{mM} \mathrm{Na}_{2} \mathrm{SO}_{4}$ solution with a $25 \mu \mathrm{m}$ electrode. The excitation signal amplitude was $100 \mathrm{mV}_{\mathrm{pp}}$ and frequencies in $\mathrm{Hz}$ are indicated in the figure legend. 


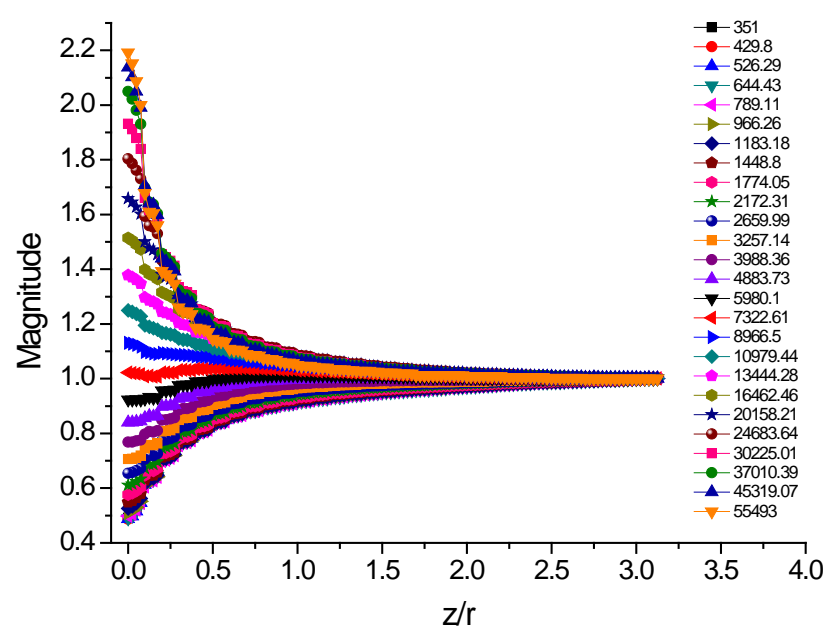

Figure 2: AC-SECM normalized Z-approach curves towards a freshly-polished $\mathrm{Cu}$ sample immersed in a $1 \mathrm{mM} \mathrm{Na}_{2} \mathrm{SO}_{4}$ solution with a $25 \mu \mathrm{m}$ electrode. The excitation signal amplitude was $100 \mathrm{mV}_{\mathrm{pp}}$ and frequencies in $\mathrm{Hz}$ are indicated in the figure legend. The sample was left at its spontaneous open circuit potentials in the test electrolyte.
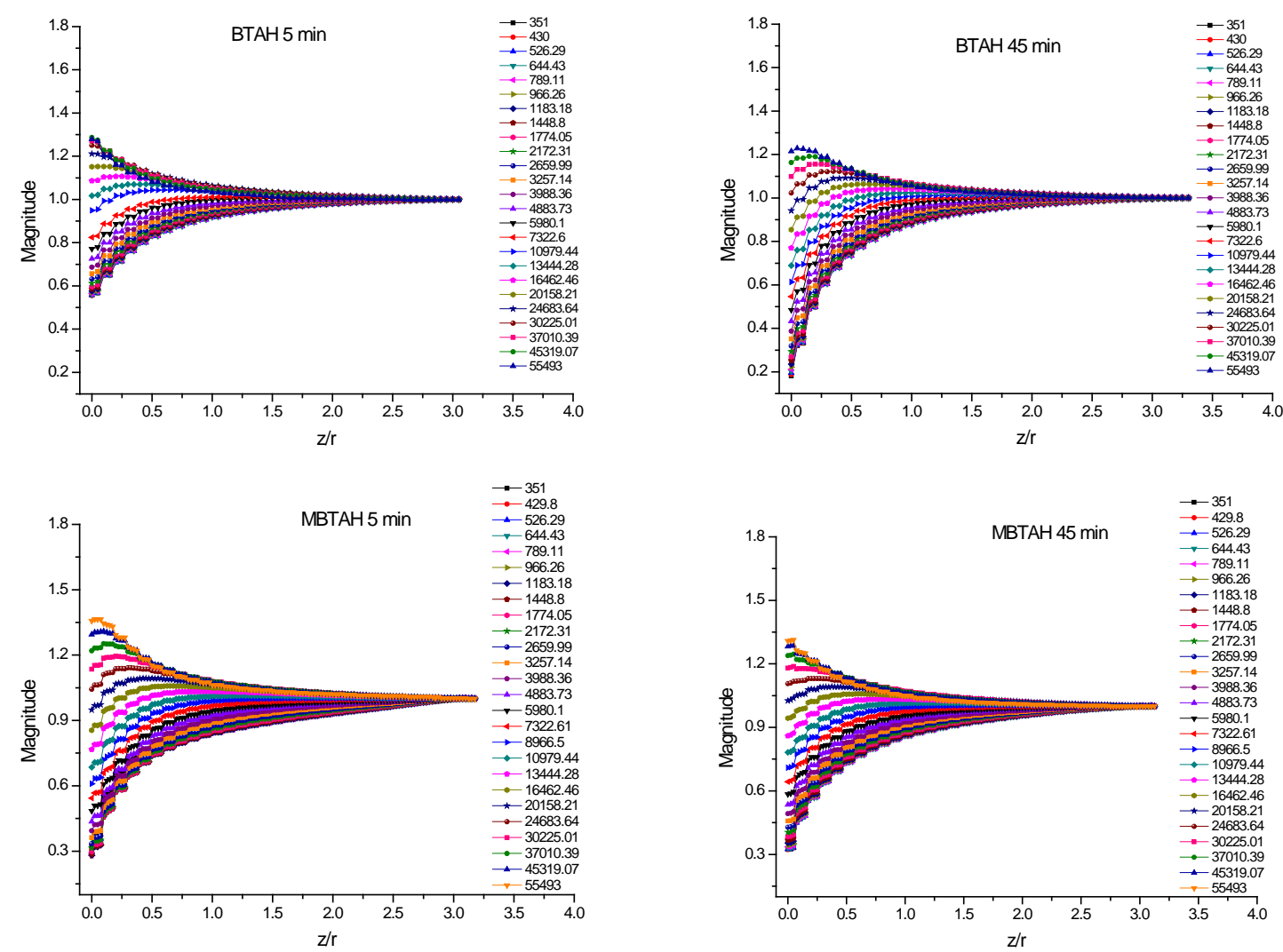

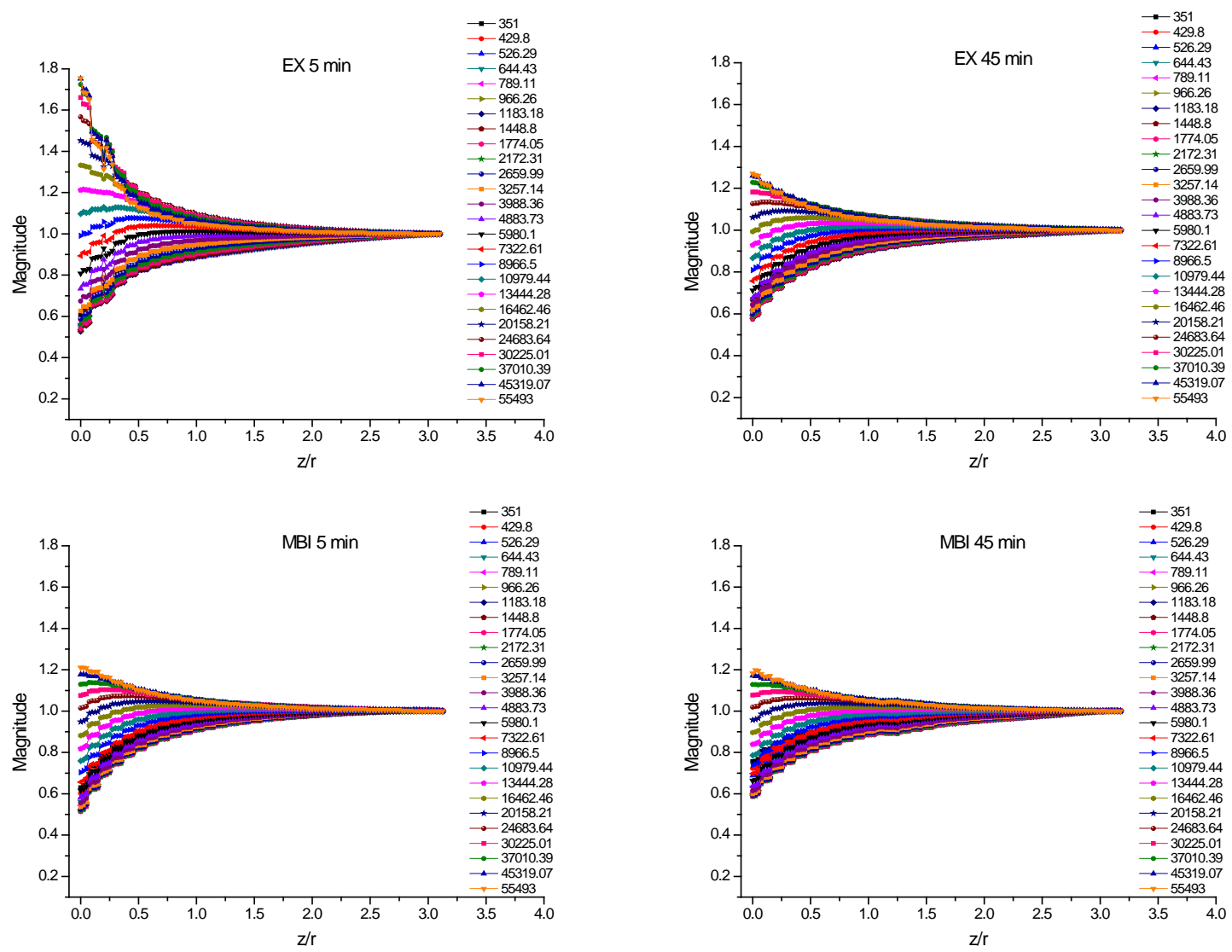

Figure 3: AC-SECM normalized Z-approach curves towards inhibitor-treated Cu samples immersed in a $1 \mathrm{mM} \mathrm{Na}_{2} \mathrm{SO}_{4}$ solution with a $25 \mu \mathrm{m}$ electrode. The inhibitors used and the duration of pretreatments in the inhibitor-containing solutions are indicated in the figure. The excitation signal amplitude was $100 \mathrm{mV}_{\mathrm{pp}}$ and frequencies in $\mathrm{Hz}$ are indicated in the figure legend. The samples were left at their spontaneous open circuit potentials in the test electrolyte. 

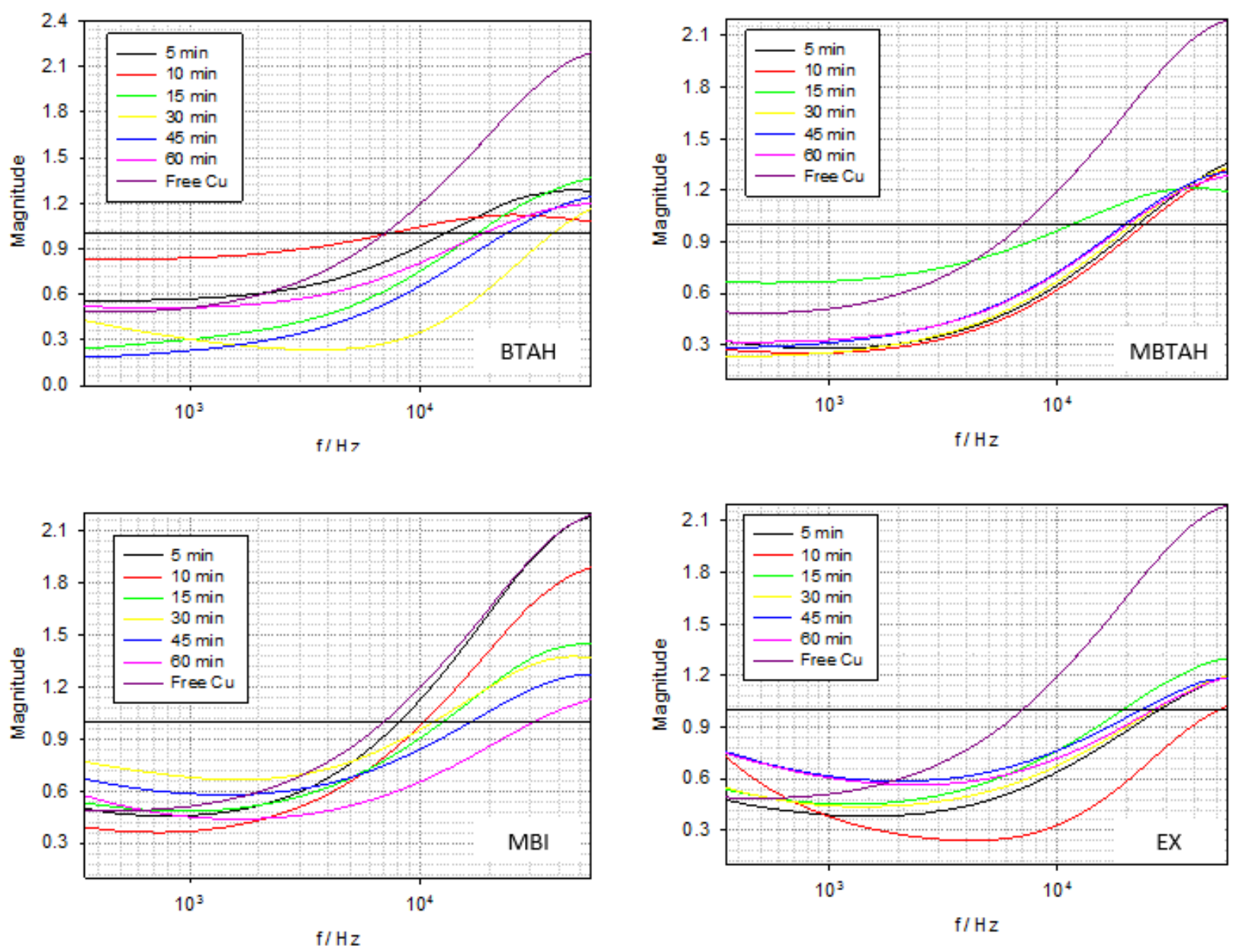

Figure 4: Frequency dependence of the normalized current magnitude values determined from Zapproach curves towards inhibitor-treated $\mathrm{Cu}$ samples immersed in a $1 \mathrm{mM} \mathrm{Na}_{2} \mathrm{SO}_{4}$ solution with a $25 \mu \mathrm{m}$ electrode. The inhibitors used and the duration of pre-treatments in the inhibitor-containing solutions are indicated in the figure. For the sake of comparison, the frequency dependence of the normalized currents for a freshly polished copper sample immersed in the test solution has also been included in the graphs. 